UDC 536.46.:532.517.4

\title{
Simulation of the aerodynamics and combustion of a turbulent pulverized-coal flame
}

\author{
N.V. Pilipenko \\ Faculty of Physics and Engineering, St. Petersburg National Research University \\ of Information Technologies, Mechanics, and Optics (ITMO), \\ 9, Lomonosov Str., 191002 St. Petersburg, Russia \\ e-mail: pilipenko38@mail.ru
}

\begin{abstract}
Using the three-dimensional modeling method, numerical experiments on flame combustion of pulverized-coal fuel have been performed. The results of a three-dimensional numerical simulation of flow aerodynamics, temperature and carbon oxides are presented. Studies have been carried out for a pulverized-angle flame of various dispersity. In the study of a wide range of modern problems of science and technology, numerical simulation of heat and mass transfer process is particularly important and has enormous practical application. Interaction of reacting flows is described by a complex system of nonlinear partial differential equations. Indispensable effective method of theoretical study of such flows is a numerical simulation. Recent results obtained in the course of this article allow solving the scientific and engineering issues, choosing the optimal option of the combustion process organization to increase its efficiency, minimize harmful gaseous and particulate emissions and reduce the negative impact on the environment. Addressing these issues is relevant in respect to the concept of energy safety of the country on the one side and the development of processes of "clean combustion" of fuel to meet strict standards of harmful substances emission into the atmosphere and economy use the equipment, on the other side.
\end{abstract}

Key words: simulation, coal combustion, aerodynamics, monodisperse flame, polydisperse flame, concentration fields. PACS number(s): 47.27, 47.70.Pq

\section{Introduction}

Numerical modeling is sufficiently accurate and inexpensive way to analyze complex processes that occur during combustion of the fuel in the combustion chambers of real power plants, and it allows to simultaneously consider the complex of processes that are almost impossible to do, conducting in situ experiments. Only the numerical modeling and carrying out computational experiments optimally solve scientific and project engineering tasks in this area (improvement, design of new boilers; burners upgrade; development of multistage fuel combustion systems, optimization of combustion processes and other) [1,2].

At the present stage of development of the energy industry, immediate consideration and resolution of environmental issues are required. Due to the fact, that for most countries the main sources of pollutant emissions into the atmosphere are companies operating in the burning of low-quality raw materials as well as with poorly equipped with flue gas cleaning systems, the problem of pollution of the Earth's atmosphere is an urgent.
Environmentally hazardous emissions, which are products of coal combustion [3-5] reactions cause enormous damage to the earth's ecosystem. It is therefore necessary to carry out a detailed study of physical and chemical processes that occur during combustion of energy fuels and to solve the problem of environmentally "pure" making use of coal $[6,7]$.

\section{Methodology of investigation}

For carrying out computational experiment the combustion chamber of the real power boiler BKZ160 Almaty TPP-3 (Kazakhstan) was selected. The boiler BKZ-160 of drum-type furnace with dry slag removal has a calculated steam generating capacity $160 \mathrm{t} / \mathrm{h}$ at a pressure of $9.8 \mathrm{MPa}$ and a temperature of the superheated steam $540{ }^{\circ} \mathrm{C}$. The boiler has a Ushaped profile with a rectangular prism furnace. Combustion chamber volume is $790 \mathrm{~m} 3$. On the sides of the combustion chamber located four blocks direct flow slot burners (two burners in the block) which directed at a tangent to the circle with a diameter of one meter. Each burner has a fuel mixture channel and two secondary air channel, they 
are located from above and from below the channel of air-fuel mixture, and divided lined piers. The top and bottom burners are also divided by a pier. In the center of burners is located oil-fired nozzle for lighting and lighting of the flame. The performance of each of the eight coal-fired burner fuels is $4 \mathrm{t} / \mathrm{h}$.

Computational experiments on research heat and mass transfer processes have been carried out by the starting FLOREAN [8] software package, the geometry of the combustion chamber was created by a computer program «PREPROZ» (Figure 1b). The software package FLOREAN was created to solve problems in the field of burning solid fuel and was repeatedly tested in many modern studies [1-12]. During the numerical simulation of heat and mass transfer process, the control volume method has been applied. Combustion chamber of a power boiler BKZ-160 has been divided into control volumes; it is possible to obtain 217536 computational areas.

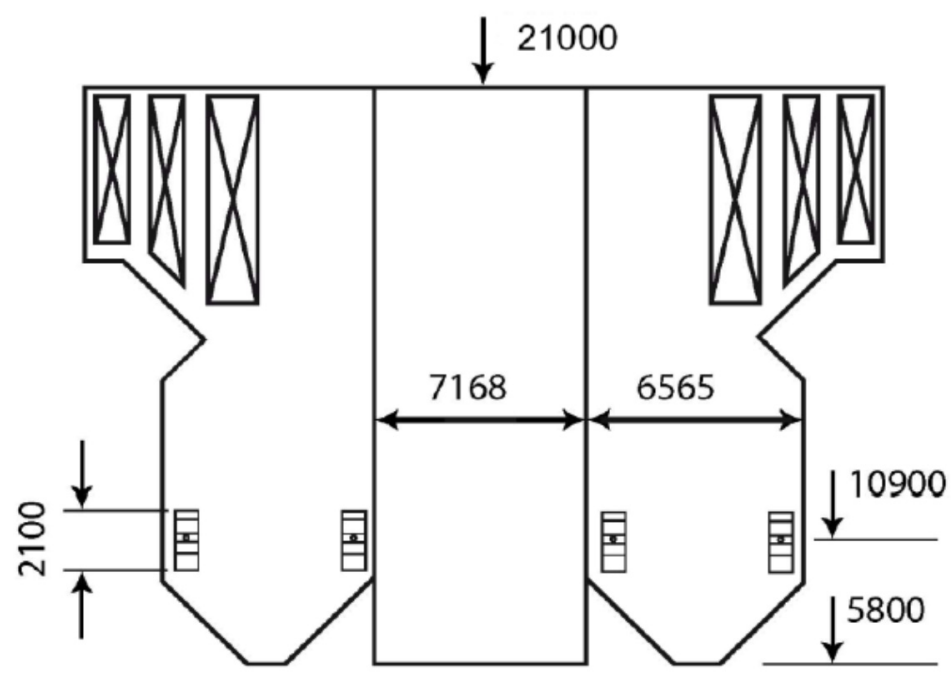

a)

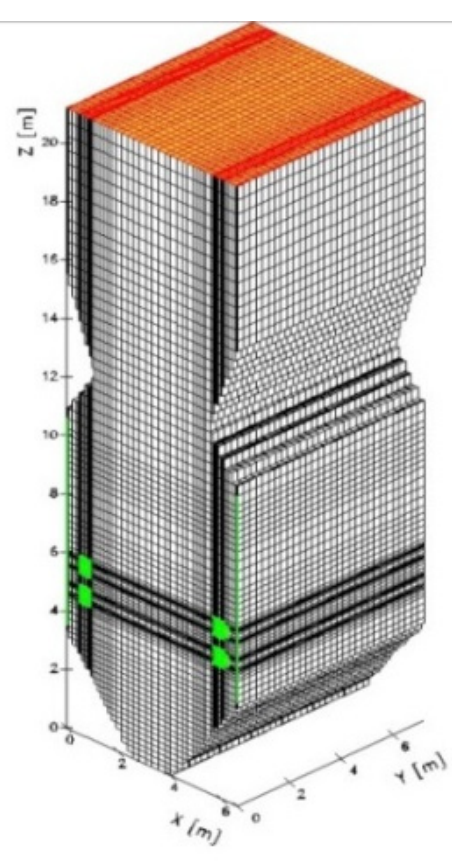

b)

Figure 1 - a) Scheme of the furnace, b) General view of the camera, broken down into control volumes

Numerical simulation was carried out on the basis of solutions of the Navier-Stokes equations, equations of heat diffusion and diffusion of components of the reacting mixture and the reaction products based on thermal radiation and multiphase media, equations of state, and chemical kinetics equations defining the intensity of nonlinear energy and matter [8, 13-15].

For a qualitative description of combustion processes in a real three-dimensional physical and chemical system (combustion chamber of Thermal power plant) in the present work a numerical calculation of a turbulent pulverized coal flame was carried out taking into account the dispersion of coal. The percentage distribution of carbon particles in size: $d_{p}=10 \mathrm{mkm}-10 \% ; d_{p}=30 \mathrm{mkm}-20 \%$; $\mathrm{d}_{\mathrm{p}}=60 \mathrm{mkm}-40 \% ; \mathrm{d}_{\mathrm{p}}=100 \mathrm{mkm}-20 \% ; \mathrm{d}_{\mathrm{p}}=120$ $\mathrm{mkm}-10 \%$ corresponds to a polydisperse flame, $\mathrm{d}_{\mathrm{p}}=60 \mathrm{mkm}-100 \%-$ is the averaged diameter, which corresponds to a monodisperse flame. Numerical calculation in the work was carried out for the two cases listed above.

\section{Results of numerical simulation}

Let us consider the profiles of aerodynamics combustion of a turbulent pulverized flame in different sections along the length of the flame. Figure 2 shows the distribution of the full-velocity vector in the longitudinal section of the furnace during combustion of a monodisperse and polydisperse flames. Obtained velocity fields allow us to visually analyze the aerodynamics of reacting flows in the combustion chamber. The fields of the 
full-velocity vector show the value of the flow velocity of the medium and its direction at each point.

In the Figure 2 the area of fuel and oxidizer is clearly visible: counter dust and gas streams from opposing tangential burners create a vortex in the central part on the location of burners and level of active burning zone. Clearly visible is the recirculation zone with reverse gas currents [15]. Part of the flow is directed down to the funnel, forming two symmetrical vortex in the area below the burner arrangement, it is typical both for burning of a monodisperse flame and for burning of a polydisperse flame. However, in a longitudinal section of the combustion chamber symmetry is broken relative to the vertical axis of the chamber when burning polydisperse flame (Figure 2b). It means that burning of dust and gas streams with different particle sizes affects to the character of the flow stream.

In cross-section chamber at a level between the lower and upper tiers of burners there is a clear picture of the current (Figure 3). The pulverized coal streams flowing into the chamber deviate from the direction of the burner axes (located tangentially) towards the adjacent walls, with which they make up a smaller angle. Fusing into the total flow, the jets create a volumetric vortex with a vertical axis of rotation, which, as it rises, untwists and then moves along the axis, as can be seen clearly in Figure 2 .

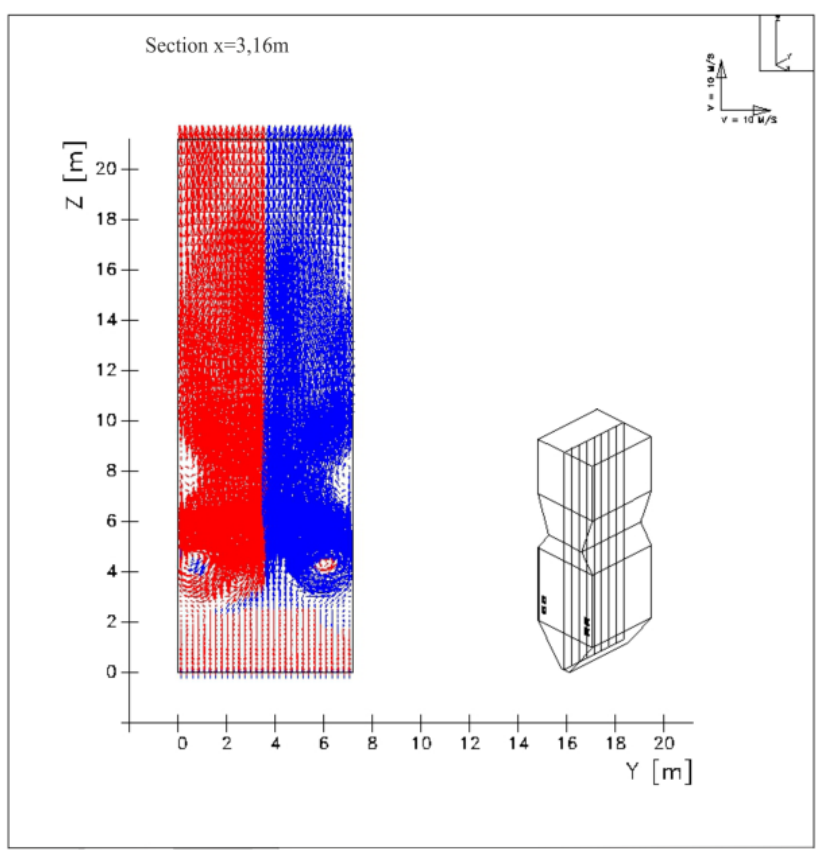

a)

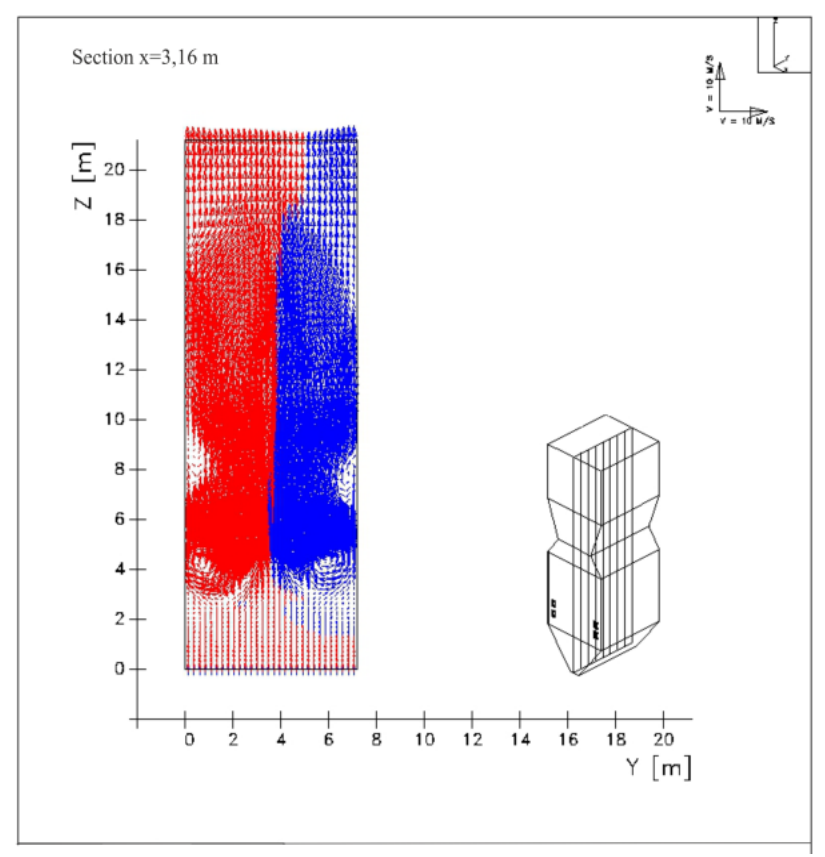

b)

Figure 2 - Field of a vector of full velocity in the longitudinal section of the combustion chamber $(\mathrm{x}=3.16 \mathrm{~m})$ for a) monodisperse flame; $\mathrm{b})$ polydisperse flame

The central vortical motion of the pulverized coal stream leads to uniform heating of the combustion chamber walls, to a decrease in the slagging of the heat shields and heat losses, which prolongs the life of individual elements of the boiler plant, and also increases the heat removal surface, which speaks of the advantages of the furnaces with the tangential arrangement of the burners. The aerodynamics of flow in the combustion of monodispersed and polydispersed flames has some differences; however, if it is necessary to make quick estimates, in numerical simulation of the aerodynamic characteristics of the coal combustion process, one can use the model of burning a particle of averaged size, which in turn reduces the expenditure of computer time [1,16-21].

Being the UNFCCC framework (the United Nations Framework Convention on Climate 
Change) since 1995 and the Kyoto Protocol since 2009, Kazakhstan has a principled position and pursues a consistent policy in the field of preventing global climate change, in the field of reducing the carbon intensity of the economy and in the field increasing energy efficiency, creating conditions for the transition to technologies for environmentally "pure" burning of energy fuel [22]. In this connection, the study of the concentration characteristics of greenhouse gases is an urgent task. Figures 4, 5, 7 show a comparative analysis of carbon oxide concentration distributions for the case of a polydisperse and monodisperse flare.

Analyzing the Figure 4 it can be argued, the nature and pattern of carbon monoxide $\mathrm{CO}$ and carbon dioxide $\mathrm{CO}_{2}$ are different from each other. Concentration of carbon oxide reaches area of the maximum values in a zone of active burning, unlike carbon dioxide which concentration increases as it moves out of the combustion chamber.

Concentrations of poly- and monodisperse flames in the field of an arrangement of burners do not differ. The average value of the concentration of carbon monoxide for polydisperse flame in the first tier of burners $(\mathrm{z}=4,81 \mathrm{~m})$ is $0,184 \cdot 10^{-2} \mathrm{~kg} / \mathrm{kg}$, for monodisperse is $0,185 \cdot 10^{-2} \mathrm{~kg} / \mathrm{kg}$, in the second tier $(\mathrm{z}=5,79 \mathrm{~m})$ is $0,279 \cdot 10^{-2} \mathrm{~kg} / \mathrm{kg}$ both for poly- and for monodisperse flames (Figure 4a). In the area of active burning the concentration of carbon monoxide $\mathrm{CO}$ reaches the maximum value, chemical processes of formation of carbon monoxide $\mathrm{CO}$ fade to output from the combustion chamber, for polydisperse flame at the exit of the combustion chamber the mean value is $1,35 \cdot 10-4$ $\mathrm{kg} / \mathrm{kg}$, for monodisperse is $0,6110-4 \mathrm{~kg} / \mathrm{kg}$ (Figure 4a).

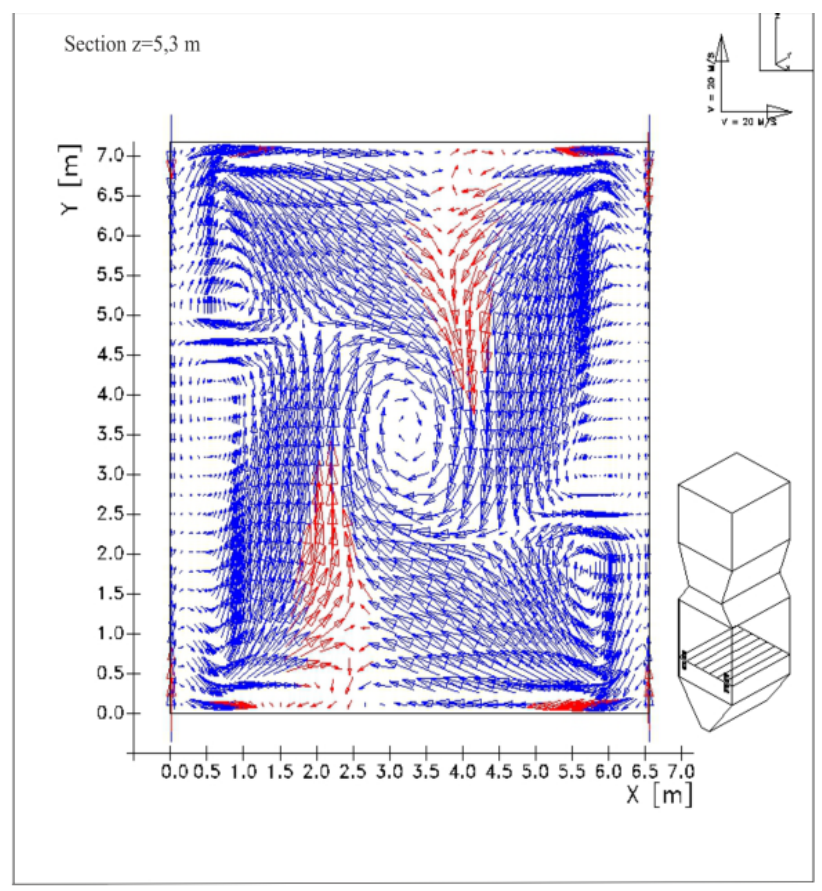

a)

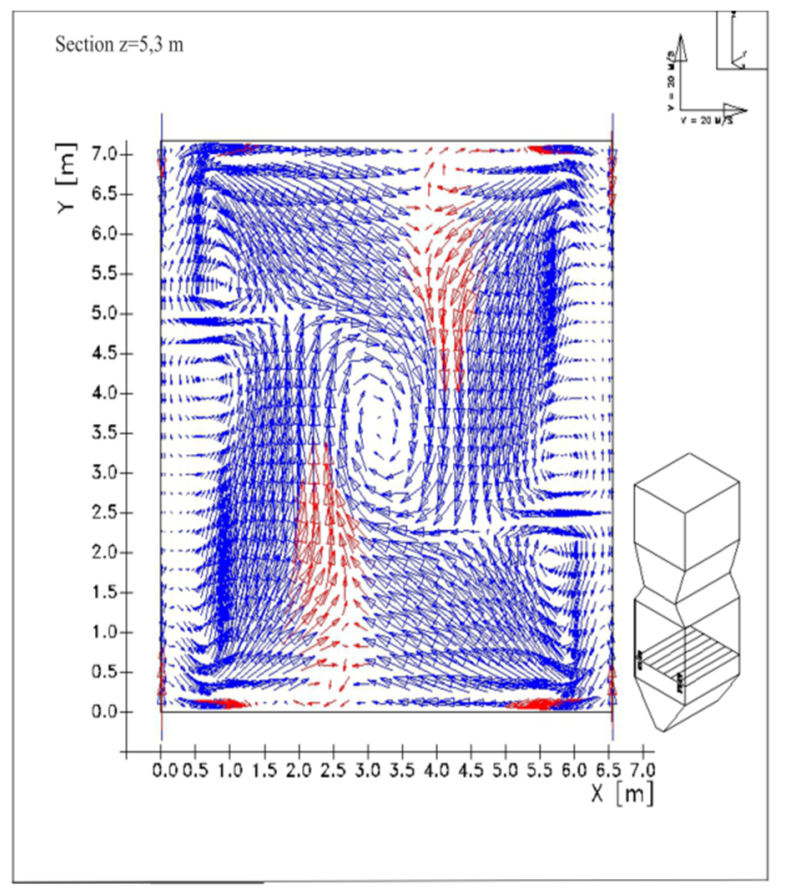

b)

Figure 3 - Field of a vector of full velocity in the cross-section of the combustion chamber $(\mathrm{z}=5.3 \mathrm{~m})$ for $\mathrm{a})$ monodisperse flame; $\mathrm{b})$ polydisperse flame 

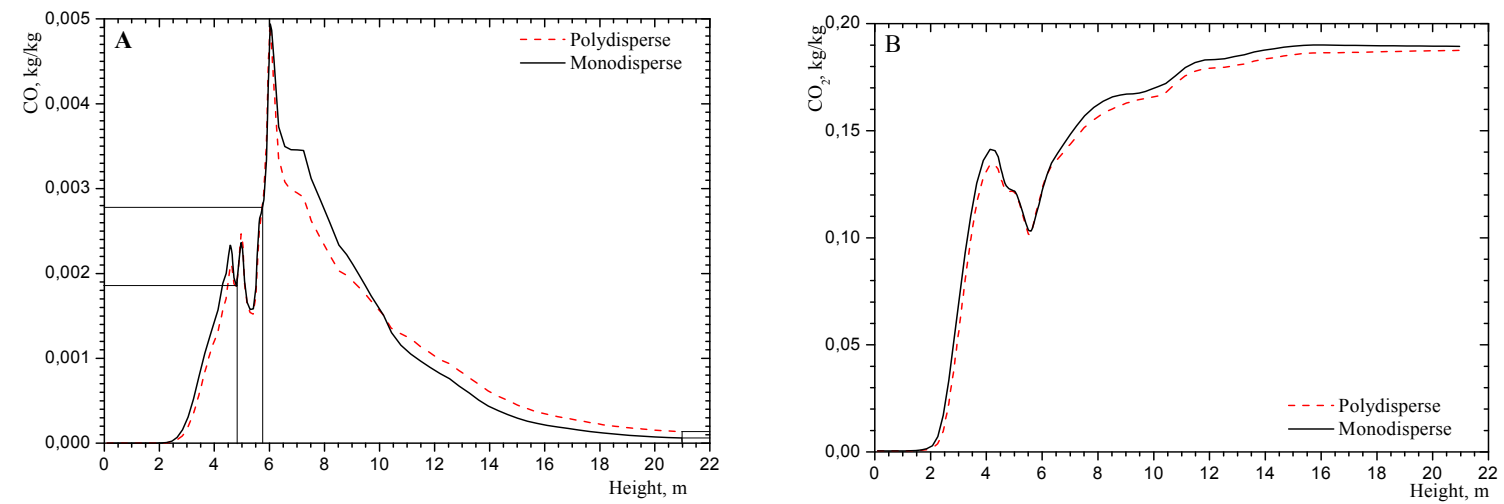

Figure 4- Comparison of the average values of concentration $\mathrm{CO}(\mathrm{A})$ и $\mathrm{CO}_{2}(\mathrm{~B})$

for poly- and monodisperse flame on height of the combustion chamber

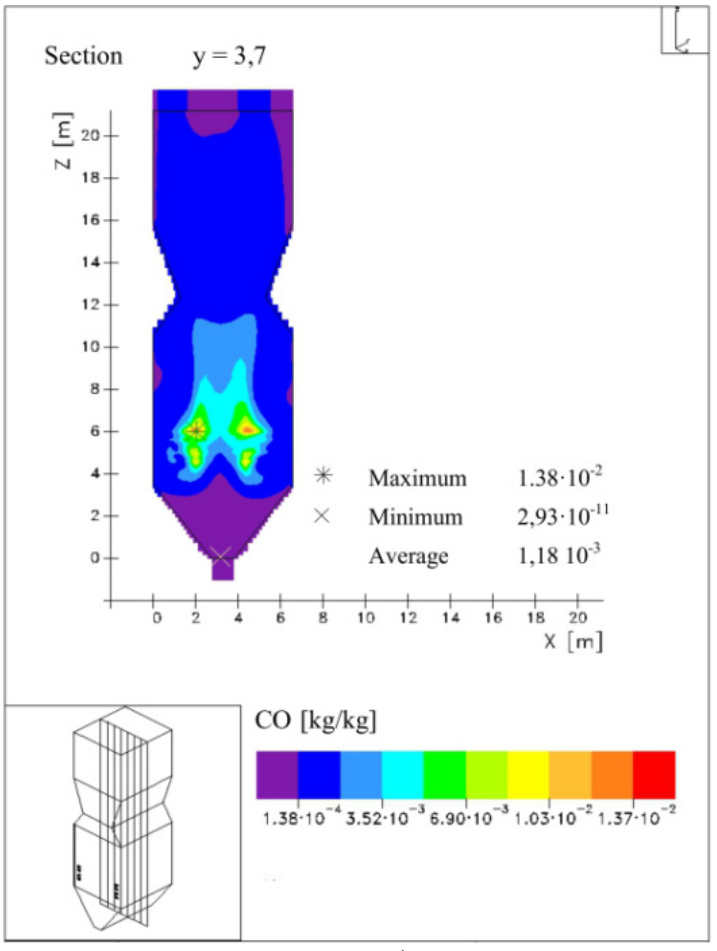

a)

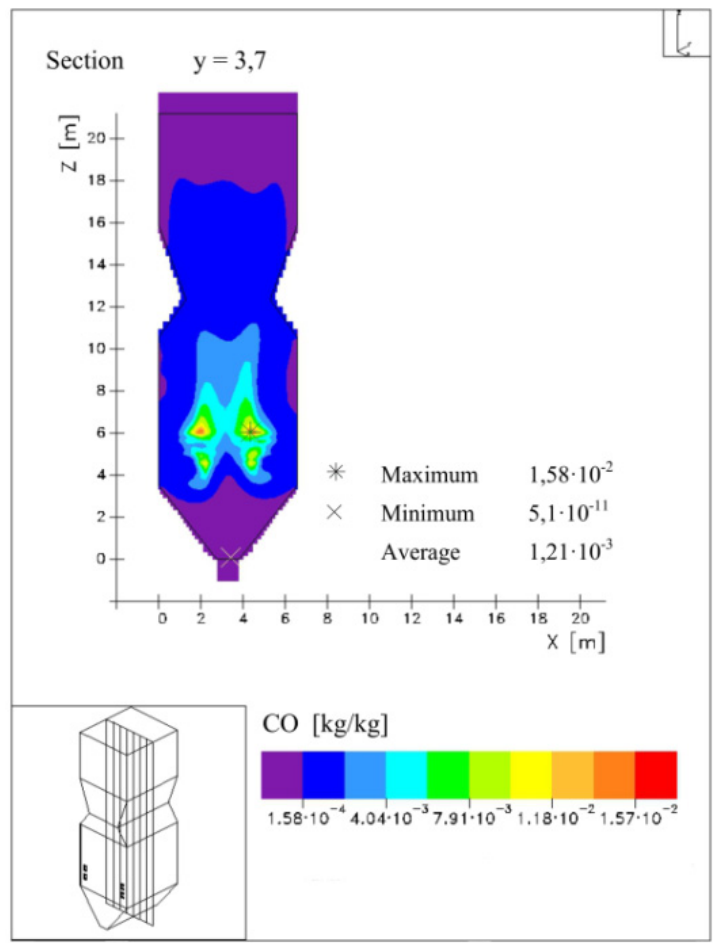

b)

Figure 5 - Distribution of the carbon oxide concentrati on in the longitudinal section of the furnace combustion chamber $(y=3.7 \mathrm{~m})$ for a) monodisperse flame; $b$ ) polydisperse flame 

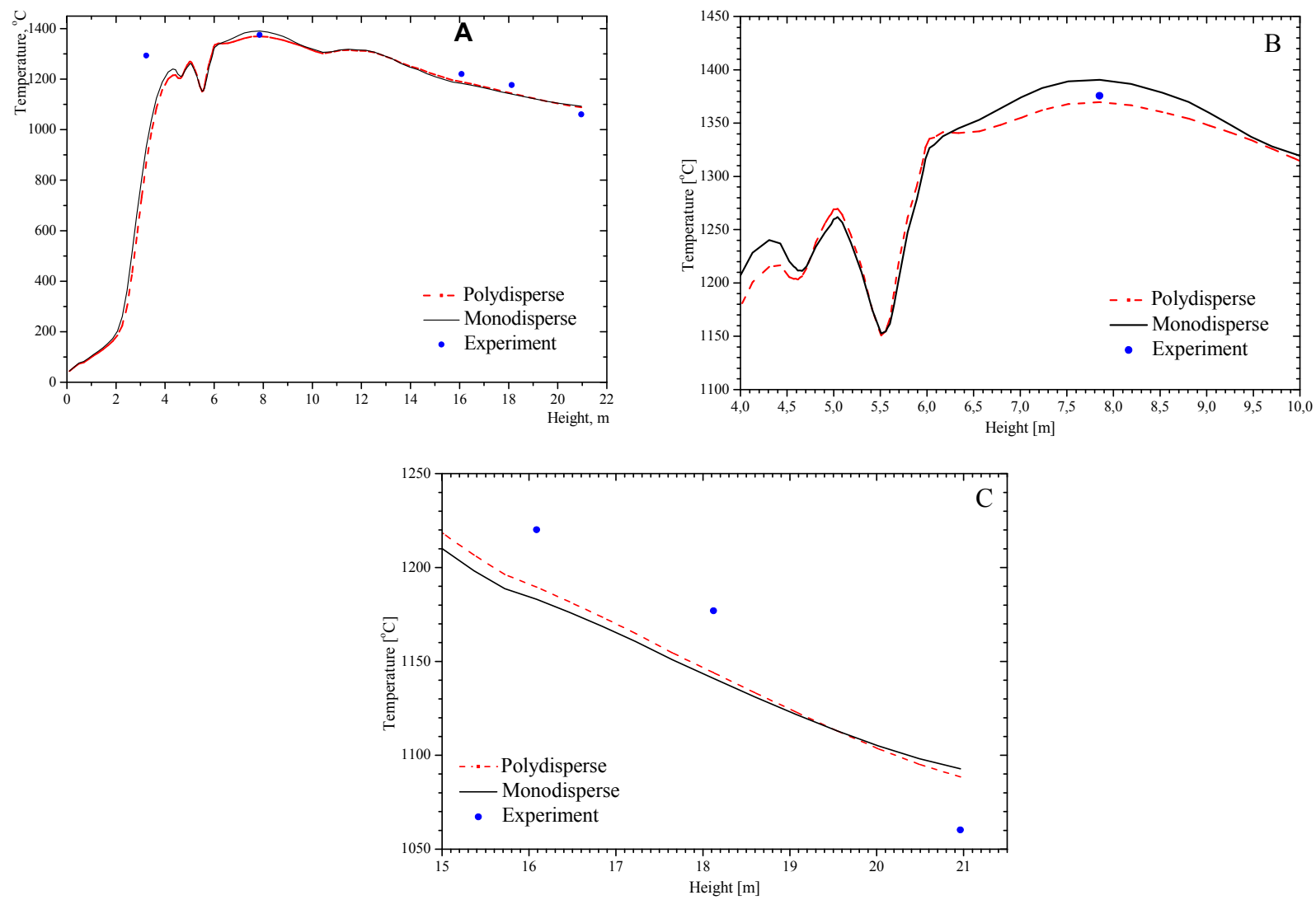

Figure 6 - Comparison of average temperature values for poly- and monodisperse flames and a comparison with the field experiment [23]: A) on height of the combustion chamber B) zone of active burning C) at the outlet of the combustion chamber

Analyzing the distribution of $\mathrm{CO}$ concentration in the longitudinal sections of the combustion chamber (Figure 5), it can be said that in the active combustion zone, there is a clear difference in the formation of $\mathrm{CO}$ for a mono- and polydisperse flames, which indicates that the particle size has a significant effect on the formation of reaction products. The maximum values of carbon monoxide $\mathrm{CO}$ are explained by the intensive physico-chemical interaction between the fuel carbon and air oxygen, and with increased temperatures in this region (Figure 6).

Figure 6 shows the experimental points obtained directly from measurements at the termal power plant [23]. It is confirmed that the numerical simulation results are in good agreement with the results of a natural experiment. It is leading to the conclusion of the applicability of the proposed physical-mathematical model of combustion processes, used in the present work. It should also be noted that the experimental data obtained directly from TPP-3 lie closer to the temperature curve of the polydisperse flame, from which it can be argued that the polydisperse flame model is more sensitive and reflects a more real process of burning pulverized coal at Almaty TPP-3.

Analyzing Figures $4 \mathrm{~b}$, and 7 it can be said that as flow moves out of the combustion chamber $\mathrm{CO}_{2}$ is restored from $\mathrm{CO}$, this regularity is fair both for monodisperse, and for polydisperse flames. It is possible to determine value of concentration in any point of furnace by a color scale of the received figures which is not always possible to obtain during the field experiments on the thermal power plant. So the average values of carbon dioxide $\mathrm{CO}_{2}$ in the longitudinal section of the combustion chamber $(\mathrm{y}=$ $3,7 \mathrm{~m}$ ) for polydisperse flame is $0.155 \mathrm{~kg} / \mathrm{kg}$, for monodisperse flame is $0.158 \mathrm{~kg} / \mathrm{kg}$ (Figure 7). At the exit of the combustion chamber average concentration of carbon dioxide for polydisperse flame is $0.1876 \mathrm{~kg} / \mathrm{kg}$, for monodisperse flame is $0.1895 \mathrm{~kg} / \mathrm{kg}$. 


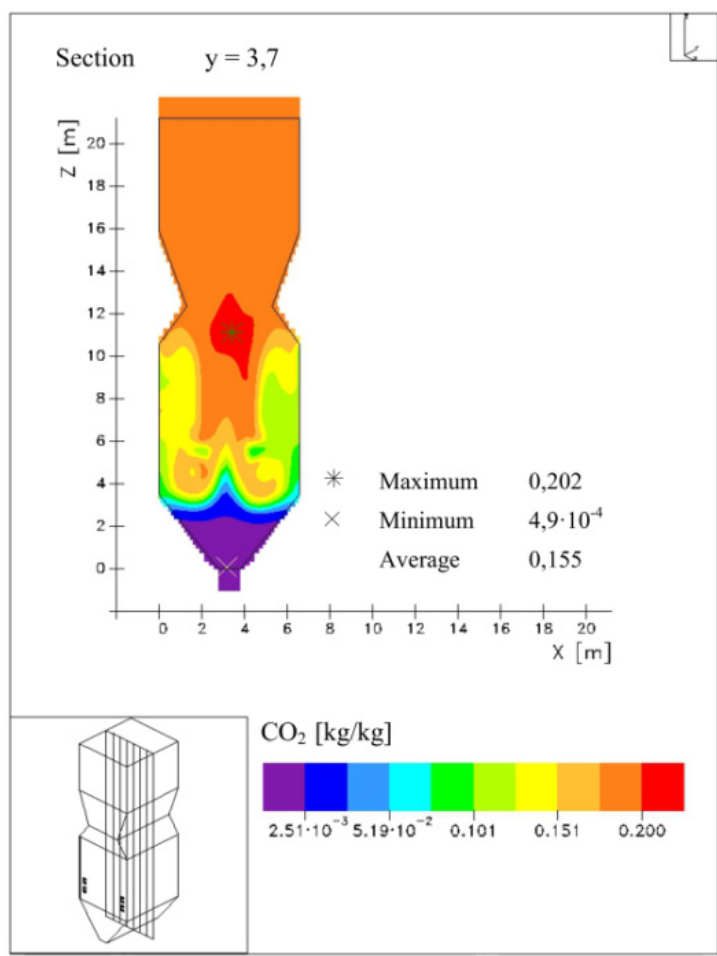

a)

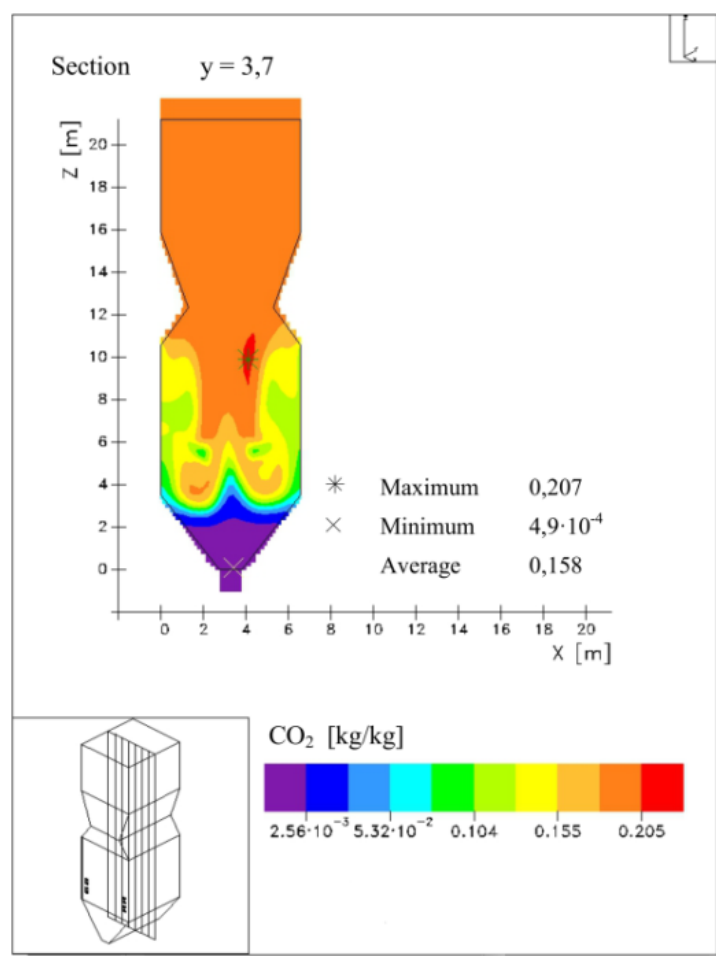

b)

Figure 7 - Distribution of carbon dioxide concentration in a longitudinal section of the combustion chamber of the combustion $(y=3.7 \mathrm{~m}$ ) for a) monodisperse flame; $\mathrm{b}$ ) polydisperse flame

\section{Conclusions}

In the present work, the calculation of aerodynamics, thermal and concentration characteristics of the combustion of mono- and polydisperse flames is performed; the results of the study can formulate the following conclusions:

1. A detailed picture of the structure of the flame is obtained, which includes a developed recirculation zone with return currents of the combustion products;

2. It is noted that the character of formation of the concentration fields $\mathrm{CO}$ and $\mathrm{CO}_{2}$ is different. The maximum concentration of carbon monoxide reaches in the zone of active combustion, and the formation of carbon dioxide $\mathrm{CO}_{2}$ increases as it moves towards the outlet from the furnace;

3. The results of computer simulation of temperature $\mathrm{T}$, were compared with the results of field experiments, the analysis of which confirms the correctness of the chosen model of numerical experiment.

In conclusion, we note that the nature of combustion of mono- and polydisperse dust has differences, i.e. The influence of fineness of grinding has a significant influence on the processes of heat and mass transfer in the combustion chamber of CHPP boilers. The combustion model of polydisperse dust more accurately reflects the actual combustion process, which confirms the comparison with the full-scale experiment. However, the application of this model requires large computer, time resources.

The results obtained in this study will give recommendations for optimizing the burning process of pulverized coal in order to reduce pollutant emissions and creations of power stations on 'pure' and an effective utilization of coal. 


\section{References}

1. A. Bekmukhamet, S. A. Bolegenova, M. T. Beketayeva et al. Numerical modeling of turbulence characteristics of burning process of the solid fuel in BKZ-420-140-7c combustion chamber// International Journal of Mechanics. - 2014. - Vol. 8. - P. 112-122.

2. A. Askarova, V. Maximov, A. Ergalieva et al. 3-D modeling of heat and mass transfer during combustion of solid fuel in Bkz-420-140-7C combustion chamber of Kazakhstan // Journal of Applied Fluid Mechanics. 2016. - Vol. 9. - P.699-709.

3. N. V. Pilipenko, I. A. Sivakov. A method of determining nonstationary heat flux and heat conduction using parametric identification// Measurement Techniques - 2011. - Vol.54. - P. 318-323.

4. N. V. Pilipenko. The systematic errors in determining the nonstationary heat-exchange conditions with parametric identification// Measurement Techniques - 2007. - Vol.50. - P. 880-887.

5. A. S. Askarova, A. Bekmuhamet, V. Yu. Maximov et al. Mathematical simulation of pulverized coal in combustion chamber // Procedia Engineering. - 2012. Vol.42. - P.1259-1265.

6. S. A. Bolegenova, V. Yu. Maximov, Z. Kh. Gabitova et al. Computational method for investigation of solid fuel combustion in combustion chambers of a heat power plant // High Temperature. - 2015. - Vol. 53. - P. 792-798.

7. M. Beketayeva, Sh. Ospanova, Z. K. Gabitova. Investigation of turbulence characteristics of burning process of the solid fuel in BKZ 420 combustion chamber // WSEAS Transactions on Heat and Mass Transfer. 2014. - Vol.9. - P. 39-50.

8. H. Müller. Numerische Berechnung dreidimensionaler turbulenter Strömungen in Dampferzeugern mit Wärmeübergang und chemischen Reaktionen am Beispiel des SNCR-Verfahrens und der Kohleverbrennung: Fortschritt-Berichte VDI-Verlag .1992. - Vol. 6. - P. 158.

9. S. Bolegenova, S. Bolegenova, A. Bekmukhamet et al. Numerical experimenting of combustion in the real boiler of CHP// International Journal of Mechanics. 2013. - Vol. 7. - P. 343-352.

10. A. Askarova, M. Beketeyeva, P. Safarik et al. Numerical modeling of pulverized coal combustion at thermal power plant boilers// Journal of Thermal Science. - 2015. - Vol. 24. - P. 275-282.

11. Ye. I. Lavrichsheva, R. Leithner, H. Müller, A. Magda et al. Combustion of low-rank coals in furnaces of Kazakhstan coal-firing power plants // VDI Berichte. 2007. - Vol. 1988 - P. 497-502.

12. Yu. E. Karpenko, V. E. Messerle, A. B. Ustimenko. et al. Mathematical modelling of the processes of solid fuel ignition and combustion at combustors of the power boilers // 7th International Fall
Seminar on Propellants. Explosives and Pyrotechnics . Xian. - 2007. - Vol. 7. - P. 672-683.

13. R. Leithner. Numerical Simulation. Computational Fluid Dynamics CFD: Course of Lecture. Braunschweig. - 2006. - P. 52.

14. S. Vockrodt, R Leithner, A. Schiller et al. Firing technique measures for increased efficiency and minimization of toxic emissions in Kasakh coal firing // VDI . 19th German Conference on Flames. Germany. VDI Gesellschaft Energietechnik. Verein Deutsch Ingenieure. Combustion and Incineration. VDI Berichte. - 1999. - Vol. 1492. - P.93-97.

15. A. S. Askarova, S.A. Bolegenova, V.Y. Maximov et al. Numerical research of aerodynamic characteristics of combustion chamber BKZ-75 mining thermal power station // Procedia Engineering. - 2012. - Vol.42. - P. 1250-12-59.

16. M. A. Buchmann, A. Askarova. Structure of the flame of fluidized-bed burners and combustion processes of high-ash coal // Gesellschaft Energietechnik. Combustion and Incineration - Eighteenth Dutch-German Conference on Flames. VDI Berichte. - 1997. Vol.1313. - P. 241-244.

17. E. I. Karpenko, V. E. Messerle, A. B. Ustimenko. Plasma enhancement of combustion of solid fuel // Journal of High Energy Chemistry. - 2006. - Vol. 40. P.111-118.

18. V. E. Messerle, A. B. Ustimenko, V. Yu. Maksimov et al. Numerical simulation of the coal combustion processinitiated by a plasma source // Thermophysics and Aeromechanics. - 2014. - Vol. 21. P. 747-754.

19. A. S. Askarova, V. E. Messerle, A. B. Ustimenko et al. Numerical simulation of pulverized coal combustion in a power boiler furnace //High Temperature. - 2015. - Vol. 53. - P. 445-452.

20. M. Gorokhovski, A. Chtab-Desportes, I. Voloshina, A. Askarova. Stochastic simulation of the spray formation assisted by a high pressure // AIP Conference Proceedings. Xian. - 2010. - Vol. 1207. P. 66-73.

21. E. I. Heierle, S. A. Bolegenova, V. Ju. Maximov, S. A. Bolegenova, R. Manatbayev, M. T. Beketaeva, A. B. Ergalieva. CFD study of harmful substances production in coal-fired power plant of Kazakhstan // Bulgarian Chemical Communications. - 2016. - Special Issue E. - P. 260-265.

22. N. V. Pilipenko, D. A. Gladskikh. Determination of the Heat Losses of Buildings and Structures by Solving Inverse Heat Conduction Problems // Measurement Techniques. - 2014. - Vol.57. - P. 181-186.

23. B. K. Alijarov, M. B. Alijarova. Combustion of Kazakh Coals in Thermal Power Stations and LargePower Boiler Houses. Almaty. - 2011. - P. 306. (in Russian). 